\title{
Birth Outcomes of Pre-Eclamptic Pregnant Women With Vitamin E Supplementation - A Population-Based Study
}

\author{
Liza Bártfai ${ }^{1}$, Andrew E. Czeizel ${ }^{* 2}$ and Ferenc Bánhidy ${ }^{3}$
}

${ }^{I}$ Department of Pulmonology, Elisabeth Teaching Hospital, Sopron, Hungary; ${ }^{2}$ Foundation for the Community Control of Hereditary Diseases, Budapest, Hungary; ${ }^{3}$ Second Department of Obstetrics and Gynecology, Semmelweis University, School of Medicine, Budapest, Hungary

\begin{abstract}
Objectives. To study the efficacy of vitamin E supplementation for the reduction of preterm birth/low birthweight newborns in pre-eclamptic pregnant women. Design. Comparison of the rate of preterm birth and low birthweight in pre-eclamptic pregnant women with or without vitamin E treatment. Setting. Hungarian Case-Control Surveillance System of Congenital Abnormalities, 1980-1996. Population. Newborn infants in Hungarian population. Methods. Medically recorded pre-eclampsia and birth outcomes of pregnant women were evaluated. Main outcome measures. Preterm birth, low birthweight. Results. There was no lower incidence of pre-eclampsia after vitamin E treatment. Pregnant women with pre-eclampsia and without vitamin E treatment had a higher rate of preterm births (10.4\% vs. 9.3\%) and low birthweight newborns $(7.8 \%$ vs. $5.6 \%)$ than the reference sample of 34,928 pregnant women without pre-eclampsia and without vitamin E treatment. The newborns of 936 pregnant women with pre-eclampsia and without vitamin E treatment had higher rate of preterm birth $(10.4 \%$ vs. $8.6 \%$; OR with $95 \%$ CI: $0.8,0.7-0.9)$ than 81 pregnant women with pre-eclampsia but with vitamin $\mathrm{E}$ treatment. However, the rate of low birthweight newborns was somewhat but not significantly higher (8.6\% vs. 7.8\%; OR with $95 \mathrm{CI}: 1.1,0.8-1.4)$ in pregnant women with pre-eclampsia and with vitamin E treatment. There was very high rate of threatened abortion $(45.7 \%$ vs. $15.3 \%)$ and threatened preterm delivery $(27.2 \% v s .13 .5 \%)$ in 81 preeclamptic pregnant women with vitamin E treatment compared to the reference group. Conclusions. Vitamin E treatment reduced the rate of preterm birth in pregnant women with pre-eclampsia but not the rate of low birthweight newborns.
\end{abstract}

Keywords: Pre-eclampsia, vitamin E, preterm birth, low birthweight.

\section{INTRODUCTION}

Pre-eclampsia (PE) is a frequent severe complication of pregnancy, and this multisystem disorder of pregnancy is characterized by pregnancy induced hypertension and newonset proteinuria during the second half of pregnancy [1]. On the one hand PE associates with serious maternal complications such as eclampsia and HELLP syndrome with high maternal mortality [2]. On the other hand, since delivery is the only cure of PE, there is a higher risk of preterm births up to $15 \%$ with an increase in infant mortality and morbidity [3].

Previously vitamin E treatment (VET) was used for the prevention of pregnant women with recurrent and threatened abortion, in addition with threatened premature labor, but no effect of VET was demonstrated in some studies [4-6], though the beneficial effect of VET for fetal growth was also shown [7].

Later some important hypotheses have been generated for the pathogenesis of $\mathrm{PE}$, one of them is based on the oxidative stress in the late 1980s [8]. A randomized placebo-controlled trial showed that vitamin $\mathrm{C}$ and $\mathrm{E}$ supplementation associated with a reduction in rate of PE from $17 \%$ to $8 \%$ in 283 women at high risk of PE [9]. However, some other studies

*Address correspondence to this author at the Budapest, 1026. Törökvész lejtö 32, Hungary; Tel: 36-1-3944-712; Fax: 36-1-3944-712;

E-mail: czeizel@interware.hu did not confirm the benefit of vitamin $\mathrm{C}$ and $\mathrm{E}$ during pregnancy for the prevention of PE [10].

The objective of our study was to check the secondary effect of VET for the adverse birth outcomes of pregnant women with PE such as preterm births and low birthweight newborns in the population-based data set of the Hungarian Case-Control Surveillance of Congenital Abnormalities (HCCSCA) [11].

\section{MATERIAL AND METHODS}

The HCCSCA is based on the comparison of cases with different congenital abnormalities and their matched controls without any defect according to the exposures of their mothers during pregnancy. Cases with congenital abnormalities are selected from the Hungarian Congenital Abnormality Registry [12] for the HCCSCSA. Control newborns were selected from the National Birth Registry of the Central Statistical Office for the HCCSCA. In general, two newborns were matched individually to each case according to sex, week of birth in the year when cases were born, and district of parents' residence of cases. These controls were selected on the basis of case list forwarded by the co-workers of the HCAR to the administrators of the National Birth Registry in each quarter of the year, and after the selection of controls they provided them with name and address for the coworkers of the HCAR.

Cases were excluded from this analysis because congenital abnormalities may have a more drastic effect for birth 
outcomes than PE or VET. Thus only 38,151 control newborns without any defect of the HCCSCA, 1980-1996 were evaluated in this study.

\section{Collection of Data Regarding Exposures}

Immediately after the selection of newborns an explanatory letter was sent to the mothers explaining the purpose of the HCCSCA, and they were asked to send us the prenatal maternity logbook and all other medical records regarding the study pregnancy for three weeks. Prenatal care was mandatory for pregnant women in Hungary (if somebody did not visit prenatal care clinic, she did not receive a maternity grant and leave), thus nearly $100 \%$ of pregnant women visited prenatal care clinics, an average 7 times in their pregnancies. The first visit was between the 6th and 12th gestational week. The task of obstetricians was to record all pregnancy complications (including PE), maternal diseases and related drug prescriptions, in addition to pregnancy supplements (such as vitamin E) in the prenatal maternity logbook.

On the other hand, a structured questionnaire and a list of medicines (drugs and pregnancy supplements), maternal diseases and pregnancy complications, in addition a printed informed consent form was also mailed to the mothers. The questionnaire requested information on, among other things, maternal personal (e.g. employment status) and medical data including pregnancy complications, maternal diseases and medicine intakes during the study pregnancy according to gestational month. In order to standardize the answers, mothers were asked to read the enclosed lists as a memory aid before they replied, and to send back the filled-in questionnaire and informed consent form with their signature in our prepaid envelop.

The interval between the end of pregnancy and return of the "information package" including prenatal maternity logbook, questionnaire, etc. was $5.2 \pm 2.9$ months.

In addition, 200 non-respondent and 600 respondent mothers were visited at home by regional nurses as part of two validation studies $[13,14]$ because the committee on ethics considered this follow-up to be disturbing to the parents of all healthy children. Regional nurses helped mothers to fill in the questionnaire used in the HCCSCA, evaluated the available medical documents and obtained data regarding the lifestyle of mothers through a cross interview of fathers and other close relatives living together, and finally the socalled family consensus was recorded.

Overall the necessary information was available on $83.0 \%$ of pregnant women $(81.3 \%$ from reply and $1.7 \%$ from home visit). Here the 17 years' data of the HCCSCA between 1980 and 1996 are evaluated because the data collection has been changed since 1997 (all mothers are visited by regional nurses), and the recent data had not been validated at the time of the analysis.

\section{Diagnostic Criteria of PE}

Blood pressure and proteinuria was measured in pregnant women at their visits in the prenatal care clinics. If proteinuria was found after the 20th gestational week, pregnant women were referred to a detailed laboratory examination. PE was diagnosed in pregnant women if they had new onset hypertension and proteinuria.
The preliminary analysis of data showed that the diagnosis of PE in the questionnaire based on retrospective maternal information were not reliable, therefore we decided to evaluate only medically recorded $\mathrm{PE}$ in the prenatal maternity logbook.

In Hungary Vitamin $E^{\circledR}$ (Richter) was used as a tablet/capsule containing $100 \mathrm{mg}$ of tocopherol aceticum for oral treatment. The recommended oral treatment is 1-2 times 1-3 tablets per day. Phials of vitamin E were not used for parenteral treatment of pregnant women.

There were 4 study groups: (i) pregnant women without $\mathrm{PE}$ and without VET as reference, (ii) pregnant women without PE but with VET, (iii) pregnant women with PE and with VET and finally (iv) pregnant women with PE but without VET.

Other pregnancy complications, PE related drug treatments and other potential confounding factors such as maternal age, birth order, marital and employment status as indicators of socio-economic status [15], other maternal diseases, vitamin supplements beyond vitamin E were also evaluated.

Gestational age was calculated from the first day of the last menstrual period. The rate of low birthweight newborns (less than 2500 gram) and preterm births (less than 37 completed gestational weeks or less than 259 days) was evaluated. Both birth weight and gestational age at delivery were medically documented in the discharge summary of mothers because all deliveries took place in inpatient obstetric clinics.

\section{Statistical Analysis of Data}

We used SAS version 8.02 (SAS Institute., Cary, North Carolina, USA) for statistical analyses. The occurrence of PE and/or VET was compared in pregnant women with or without $\mathrm{PE}$ and the reference group including all pregnant women without PE and without VET. Contingency tables were prepared for the main study variables. First, the characteristics of pregnant women with different study groups were compared with the reference group using chi-square test for categorical variables, while Student t-test for quantitative variables. Second, frequency of maternal diseases, pregnancy complications and related drug treatments was compared in the different study groups by ordinary logistic regression models and odds ratios (OR) with their 95\% confidence intervals (CI) were evaluated. Fourth, the birth outcomes of newborns were evaluated in mothers with PE and with or without VET and the reference group using adjusted Student t-test and OR with $95 \% \mathrm{CI}$ in ordinary logistic regression model.

\section{RESULTS}

The total number of births in Hungary was 2,146,574 during the study period, thus 38,151 controls represented $1.8 \%$ of all Hungarian births. Of these 38,151 newborns, $1,017(2.7 \%)$ had mothers with medically recorded PE in the prenatal maternity logbook.

Of 37,134 pregnant women without PE, 2,206 (5.9\%) had VET, while of 1,017 pregnant women with PE, 81 $(8.0 \%)$ were born to mothers with VET. Thus the rate of PE was higher in pregnant women with VET. 
Table 1. Maternal Characteristics in the Study Groups

\begin{tabular}{|c|c|c|c|c|c|c|c|c|c|c|}
\hline \multirow{3}{*}{ Variables } & \multicolumn{10}{|c|}{ Pregnant Women } \\
\hline & \multicolumn{2}{|c|}{$\begin{array}{c}\text { Without PE } \\
\text { Without VET } \\
(\mathbf{N}=\mathbf{3 4 , 9 2 8 )}\end{array}$} & \multicolumn{2}{|c|}{$\begin{array}{l}\text { Without PE } \\
\text { with VET } \\
(\mathrm{N}=\mathbf{2 , 2 0 6})\end{array}$} & \multicolumn{2}{|c|}{$\begin{array}{c}\text { With PE } \\
\text { With VET } \\
(\mathbf{N}=\mathbf{8 1})\end{array}$} & \multicolumn{2}{|c|}{$\begin{array}{c}\text { With PE } \\
\text { Without VET } \\
(\mathbf{N}=936)\end{array}$} & \multicolumn{2}{|c|}{$\begin{array}{c}\text { With PE } \\
\text { With/Without VET } \\
(\mathbf{N}=\mathbf{1 , 0 1 7 )}\end{array}$} \\
\hline & No. & $\%$ & No. & $\%$ & No. & $\%$ & No. & $\%$ & No. & $\%$ \\
\hline \multicolumn{11}{|l|}{ Maternal age (yr) } \\
\hline $20-29$ & 25,263 & 72.3 & 1,615 & 73.2 & 53 & 65.4 & 672 & 71.7 & 725 & 71.2 \\
\hline 30 or more & 6,610 & 18.9 & 455 & 20.6 & 23 & 28.4 & 183 & 19.7 & 206 & 20.3 \\
\hline Mean \pm S.D. & 25.4 & 4.9 & 25.7 & 4.9 & 26.5 & 5.3 & 25.4 & 4.9 & 25.5 & 5.0 \\
\hline \multicolumn{11}{|l|}{ Birth order } \\
\hline Mean \pm S.D. & 1.8 & 0.9 & 1.6 & 0.8 & 1.4 & 0.9 & 1.4 & 0.9 & 1.4 & 0.9 \\
\hline \multicolumn{11}{|l|}{ Pregnancy order } \\
\hline 1 & 14,859 & 42.5 & 921 & 41.7 & 39 & 48.1 & 501 & 53.5 & 540 & 53.1 \\
\hline 2 or more & 20,069 & 57.5 & 1,285 & 58.3 & 42 & 51.9 & 435 & 46.5 & 477 & 46.9 \\
\hline Mean \pm S.D. & 1.9 & 1.2 & 2.0 & 1.2 & 1.8 & 1.0 & 1.8 & 1.2 & 1.8 & 1.2 \\
\hline Categorical & No. & $\%$ & No. & $\%$ & No. & $\%$ & No. & $\%$ & No. & $\%$ \\
\hline Unmarried & 1,380 & 4.0 & 63 & 2.9 & 2 & 2.5 & 27 & 2.9 & 29 & 2.9 \\
\hline \multicolumn{11}{|l|}{ Employment status } \\
\hline Housewife & 2,245 & 6.4 & 67 & 3.0 & 4 & 4.9 & 36 & 3.9 & 40 & 3.9 \\
\hline Others & 813 & 2.3 & 28 & 1.3 & 0 & 0.0 & 12 & 1.3 & 12 & 1.2 \\
\hline \multicolumn{11}{|l|}{$\begin{array}{l}\text { Pregnancy } \\
\text { supplements }\end{array}$} \\
\hline Iron & 24,264 & 69.5 & 1,772 & 80.3 & 68 & 84.0 & 670 & 71.6 & 738 & 72.6 \\
\hline Calcium & 3,276 & 9.4 & 217 & 9.8 & 9 & 11.1 & 81 & 8.7 & 90 & 8.8 \\
\hline Folic acid & 18,850 & 54.0 & 1,345 & 61.0 & 54 & 66.7 & 526 & 56.2 & 580 & 57.0 \\
\hline Vitamin C & 1,266 & 3.6 & 355 & 16.1 & 17 & 21.0 & 47 & 5.0 & 64 & 6.3 \\
\hline Multivitamins & 2,270 & 6.5 & 176 & 8.0 & 6 & 7.4 & 57 & 6.1 & 63 & 57.0 \\
\hline
\end{tabular}

Of 2,206 pregnant women without PE, 1,388 (62.9\%), while of 81 pregnant women with PE, 51 (63.0\%) had medically recorded VET in prenatal maternity logbook. The reason of VET was previous miscarriages or threatened abortion, and it explains that the obvious peak of VET occurred during the second and third gestational month (65.0\%). The late onset of VET was connected with threatened preterm delivery. The mean duration of VET was 3.3 months. The dose of VET was not mentioned in about one-third of preg- nant women, in general this VET was reported only by mothers. About half of pregnant women had daily $600 \mathrm{mg}$ of VET, i.e. $2 \times 3$ tablets. The rest used daily $2 \times 1-2$ tablets.

Maternal characteristics are shown in Table 1. The mean maternal age of pregnant women with VET was somewhat lower but pregnant women with PE and VET had significantly lower mean birth order. On the contrary the mean pregnancy order was the highest in pregnant women without PE but with VET. The difference between birth order and 
pregnancy order was only 0.1 in the reference group, however, this figure was 0.4 in pregnant women with PE with or without VET indicating a higher rate of previous miscarriages. The proportion of professional women was somewhat lower while the proportion of managerial and skilled worker women was higher in pregnant women with PE.

Folic acid and multivitamins were used more frequently by pregnant women with VET than by the reference women and pregnant women with PE but without VET.

Of 800 mothers visited at home, 29 (3.6\%) had PE, and among them $11(37.9 \%)$ were smokers, while of 771 pregnant women without PE, 141 (18.3\%) smoked.

Acute and chronic maternal diseases did not show significant differences between pregnant women with PE and the reference sample.

Pregnancy complications recorded in the prenatal maternity logbook were evaluated in the study (Table 2). The incidence of threatened abortion was somewhat higher in pregnant women with PE and without VET than in the reference group of 34,928 pregnant women without $\mathrm{PE}$ and without VET $(18.7 \%$ vs. 15.3$)$ while their rate of threatened preterm delivery was somewhat lower $(11.4 \%$ vs. $13.5 \%)$. However, the rate of threatened abortion $(45.7 \%$ vs. $15.3 \%$; OR with 95\% CI: $2.8,2.1-3.5)$ and preterm delivery $(27.2 \% v s$. $13,5 \%$; OR with $95 \%$ CI: $2.0,1.3-2.7)$ was much higher in pregnant women with PE and VET than in the reference group. However, it is worth mentioning that of 2,206 mothers with VET, $276(12.5 \%)$ had both threatened abortion and preterm delivery. The incidence of placental disorders (OR with $95 \%$ CI: $2.7,1.2-4.2$ ), and of severe nausea or vomiting (OR with 95\% CI: 1.6, 1.1-2.1) was also higher in pregnant women with VET compared to the reference group.

Practically all pregnant women with PE were treated with antihypertensive drugs, while allylestrenol, diazepam, drotaverine, promethazine were used for the treatment of threatened abortion and threatened preterm delivery.

Table 3 shows the birth outcomes of newborn infants in the study groups. There was no significant difference in the sex ratio of the study groups, while their rate of twins was about $1 \%$. First we evaluated pregnant women without PE but with or without VET, the latter as reference. The mean gestational week at delivery was 0.2 week longer in pregnant women with VET $(\mathrm{t}=4.2 ; \mathrm{p}<0.0001)$ and it associated with a significant decrease in the rate of preterm birth (OR with $95 \%$ CI: $0.7,0.6-0.8)$. The minus 8 gram in the mean birth weight of newborn infants born to mothers with VET $(\mathrm{t}=0.6$; $\mathrm{p}=0.54$ ) have no clinical importance, but the rate of low birthweight newborns was somewhat but not significantly higher (OR with $95 \% \mathrm{CI}: 1.1,0.9-1.3$ ). If only medically recorded VET was considered, there was a longer gestational age $(40.0 \mathrm{wk})$ with lower rate of preterm birth $(4.4 \%)$ in the group of pregnant women without PE.

In the second step the birth outcomes of pregnant women with PE and without VET were compared to the reference group. The mean gestational was somewhat shorter (0.1 wk), and it associated with a higher rate of preterm birth (10.4\%)

Table 2. Incidence of Pregnancy Complications in the Study Groups

\begin{tabular}{|c|c|c|c|c|c|c|c|c|c|c|}
\hline \multirow{2}{*}{$\begin{array}{l}\text { Pregnancy Complications } \\
\text { Quantitative }\end{array}$} & \multicolumn{10}{|c|}{ Pregnant Women } \\
\hline & No. & $\%$ & No. & $\%$ & No. & $\%$ & No. & $\%$ & No. & $\%$ \\
\hline Threatened abortion & 5,337 & 15.3 & 961 & 43.6 & 37 & 45.7 & 175 & 18.7 & 212 & 20.8 \\
\hline Pre-eclampsia & 0 & 0.0 & 0 & 0.0 & 81 & 100.0 & 936 & 100.0 & 1,017 & 100.0 \\
\hline Gestational hypertension & 8 & 0.0 & 2 & 0.1 & 0 & 0.0 & 0 & 0.0 & 0 & 0.0 \\
\hline Pregnancy related renal disease & 420 & 1.2 & 16 & 0.7 & 6 & 7.4 & 50 & 5.3 & 56 & 5.5 \\
\hline Placental disorders* & 486 & 1.4 & 85 & 3.9 & 13 & 16.0 & 29 & 3.1 & 42 & 4.1 \\
\hline Polyhydramios & 158 & 0.5 & 27 & 1.2 & 0 & 0.0 & 6 & 0.6 & 6 & 0.6 \\
\hline Oligohydramios & 9 & 0.0 & 4 & 0.2 & 1 & 1.2 & 0 & 0.0 & 1 & 0.1 \\
\hline Threatened preterm delivery** & 4,712 & 13.5 & 606 & 27.5 & 22 & 27.2 & 107 & 11.4 & 129 & 12.7 \\
\hline Anemia & 5,769 & 16.5 & 393 & 17.8 & 16 & 19.8 & 180 & 19.2 & 196 & 19.3 \\
\hline Others $* * *$ & 582 & 1.7 & 58 & 2.6 & 2 & 2.5 & 33 & 3.5 & 35 & 3.4 \\
\hline
\end{tabular}


(OR with 95\% CI: 1.1, 0.9-1.4). The mean birth weight of newborn infants born to pregnant women with $\mathrm{PE}$ was larger (40 g) $(\mathrm{t}=2.5 ; \mathrm{p}=0.01)$, but there was a higher rate of low birthweight in pregnant women with $\mathrm{PE}$ and without VET (7.8\%) (OR with 95\% CI: 1.4, 1.1-1.8).

In the next step the effect of VET was evaluated in pregnant women with PE compared to pregnant women with PE but without VET. The mean gestational age was longer $(0.2$ wk) and it associated with a lower rate of preterm birth (8.6\%) due to VET (OR with 95\% CI 0.8, 0.7-0.9). The difference in mean birth weight was small (plus $16 \mathrm{~g}$ ) but it is not associated with significant increase in the rate of low birthweight newborns (8.6\%; OR with 95\% CI: $1.1,0.8-1.4$ ) newborns. The number of pregnant women with $\mathrm{PE}$ and VET was limited for the separate evaluation of medically recorded VET in pregnant women with PE.

The final column of Table 3 shows the birth outcomes of pregnant women with PE with or without VET. The adverse effect of PE seems to be stronger than the benefit of VET because both the rate of preterm births and low birthweigh newborns is higher than in the reference group, i.e. pregnant women without PE and VET.

\section{DISCUSSION}

The aim of the study was to estimate the effect of VET in pregnant women with PE for preterm births and low birthweight newborns. Our study confirmed that there was no protective effect of VET for the incidence of PE, however, VET seemed to have some beneficial effect for the adverse birth outcomes of pregnant women with PE. The rate of preterm births and mainly of low birth weight was higher in the newborns of pregnant women with PE than in the newborns of pregnant women without PE, as it was found previously $[16,17]$. The longer gestational age at delivery associated with a somewhat higher rate of low birthweight, and it indicates intrauterine fetal growth retardation. However, the rate of preterm birth was reduced by concomitant VET $(8.6 \%$ vs. $10.4 \%$ ). Similar beneficial effect was not found in the rate of low birthweight in the subgroup of pregnant women with PE after VET, in fact it was somewhat higher compared to the figure of pregnant women with $\mathrm{PE}$ (8.6\% vs. 7.8\%).

Thus there was a significant reduction in preterm births of newborn infants born to pregnant women with PE due to
VET though these pregnant women had much higher incidences of threatened abortion and preterm delivery. However similar beneficial effect was not found in the rate of low birthweight.

The prevalence of PE was $2.7 \%$ in pregnant women studied, which was lower than expected figures based on about $4 \%$ of pregnancies in other studies [2], however, pregnant women with previous hypertension were excluded from the study.

The major expected benefit of antihypertensive therapy is the reduction of hypertension of pregnant women with PE; however, it was not successful in many women in our material. However, VET seems to be effective in the reduction of higher rate of preterm birth in pregnant women with $\mathrm{PE}$, but VET was not able to reduce the rate of low birthweight, i.e. VET was not protective for intrauterine fetal growth retardation.

Vitamin E levels rise throughout pregnancy in women [18]. The placental transfer of vitamin $\mathrm{E}$ is by passive diffusion; its passage to the fetus is dependent on plasma lipid concentrations. Vitamin E concentrations in pregnant women at terms are approximately 4-5 times that of the newborns [19].

In general well-nourished pregnant women consume adequate vitamin $\mathrm{E}$ in the diet and supplementation is not required [20]. In Hungary high doses (the estimated daily dose was about $450 \mathrm{mg}$ ) of VET were used in pregnant women with threatened abortion. The doses far exceeding the RDA have not proved to be harmful in previous studies [21], though recently a higher risk of cardiovascular malformations was reported after the high dose of VET in early pregnancy [22]. However, this finding was not confirmed in the population-based Hungarian case-control study [23].

The question is whether the reduced risk of preterm birth after VET in pregnant women without PE and with PE who were recorded with repeated or threatened abortion in the prenatal maternity logbook is causal or can be explained by other drug treatments, lifestyle factors, other or unevaluated confounders.

Vitamin $\mathrm{E}$ is a well-known antioxidant and its possible beneficial effect for placenta function was shown is some studies [24, 25] and placental dysfunction may have a role in

Table 3. Birth Outcomes of Newborn Infants in the Study Groups

\begin{tabular}{|c|c|c|c|c|c|c|c|c|c|c|}
\hline \multirow{3}{*}{$\begin{array}{l}\text { Birth Outcomes } \\
\text { Quantitative }\end{array}$} & \multicolumn{10}{|c|}{ Pregnant Women } \\
\hline & \multicolumn{2}{|c|}{$\begin{array}{c}\text { Without PE } \\
\text { Without VET } \\
(\mathbf{N}=\mathbf{3 4 , 9 2 8 )}\end{array}$} & \multicolumn{2}{|c|}{$\begin{array}{l}\text { Without PE } \\
\text { With VET } \\
(\mathrm{N}=2,206)\end{array}$} & \multicolumn{2}{|c|}{$\begin{array}{c}\text { With PE } \\
\text { Without VET } \\
(\mathrm{N}=936)\end{array}$} & \multicolumn{2}{|c|}{$\begin{array}{c}\text { With PE } \\
\text { With VET } \\
(\mathbf{N}=\mathbf{8 1})\end{array}$} & \multicolumn{2}{|c|}{$\begin{array}{c}\text { With PE } \\
\text { Without/With VET } \\
(\mathbf{N}=\mathbf{1 , 0 1 7})\end{array}$} \\
\hline & Mean & S.D. & Mean & S.D. & Mean & S.D. & Mean & S.D. & Mean & S.D. \\
\hline Gestational age (wk) & 39.4 & 2.1 & 39.6 & 2.0 & 39.3 & 2.1 & 39.5 & 2.0 & 39.4 & 2.0 \\
\hline Qualitative & No. & $\%$ & No. & $\%$ & No. & $\%$ & No. & $\%$ & No. & $\%$ \\
\hline Preterm birth & 3,249 & 9.3 & 143 & 6.5 & 97 & 10.4 & 7 & 8.6 & 104 & 10.2 \\
\hline Low birthweight & 1,950 & 5.6 & 137 & 6.2 & 73 & 7.8 & 7 & 8.6 & 80 & 7.9 \\
\hline
\end{tabular}

Adjusted OR with $95 \%$ CI are shown in the text, mean gestational age and preterm birth rate were adjusted for maternal age, birth order, employment status as indicator of socioeconomic status, drug treatment, and folic acid/multivitamin supplement, while mean birth weigh and low birthweight rate were adjusted for the above confounders plus gestational age. 
the origin of preterm birth. However, the incidence of PE was somewhat higher in pregnant women with VET thus preventive effect of VET for this pregnancy complication was not found in agreement with the previously mentioned other studies.

The efficacy of other drug treatments such as allylestrenol, diazepam, promethazine, drotaverine in the prevention of preterm delivery is debated. Our recent study showed that folic acid in the third trimester of pregnancy can reduce the rate of preterm birth [26] and folic acid was used more frequently by pregnant women with VET. However, folic acid and/or multivitamins were considered among confounders.

Several factors are known in the origin of miscarriages, but chromosomal aberrations represent the most common group. Obviously VET is not appropriate for the prevention of chromosomal aberrations related miscarriages. However, threatened abortions may have several other causes and only birth outcomes were evaluated in the study. Thus a reasonable hypothesis is that seriously affected fetuses selected out before birth and only surviving fetuses could be evaluated in the study and VET may have beneficial effect for these fetuses.

Another possible explanation for the lower risk of preterm birth is the more health conscious' behaviour, thus healthier lifestyle and/or the better prenatal care. However, the healthier lifestyle of pregnant women with PE was not confirmed because they had a higher proportion of smokers. The higher use of folic acid and other pregnancy supplements in pregnant women with VET may be connected with the better prenatal care. Finally the effect of other or unevaluated confounders cannot be excluded.

On the contrary of the above dilemmas, the old fashion VET may be useful in the reduction of preterm birth in pregnant women with $\mathrm{PE}$, though a reduction in the rate of low birthweight newborns cannot be expected.

The strengths of the HCCSCA are that is a populationbased large data set including 1,017 pregnant women with prospectively and medically recorded PE and 2,287 pregnant women with VET in an ethnically homogeneous European (Caucasian) population. We were able to differentiate PE from the other types of hypertension in pregnant women and to evaluate medically recorded VET separately. Additional strengths are medically recorded other pregnancy complications and birth outcomes, in addition the available data of potential confounders.

However, this data set also has limitations. (i) Other pregnancy outcomes, e.g. miscarriages were not known. (ii) Lifestyle factors could not be evaluated in the total data set due to the unreliability of maternal self-reported data [27], only in a subsample visited at home.

In conclusion, a higher risk of preterm births and mainly low birthweight was found in the newborns of pregnant women with PE. VET was able to reduce the rate of preterm birth in pre-eclamptic pregnant women with threatened abortion and preterm delivery but beneficial effect for the higher rate of low birthweight in newborn infants born to mothers with PE was not found.

\section{ACKNOWLEDGEMENTS}

Authors thank Erzsébet H. Puho for the statistical analysis of data.

\section{DECLARATION OF INTEREST}

The authors report no conflicts of interest.

\section{ABBREVIATIONS}

CI:

$=$ Confidence interval

HCAR

$=$ Hungarian Congenital Abnormality Registry

HCCSCA = Hungarian Case-Control Surveillance of Congenital Abnormalities

OR

PE

$=$ Odds ratio

VET

$=$ Pre-eclampsia

\section{REREFENCES}

[1] Brown MA, Lindheimer MD, de Swiet M, et al. The classification and diagnosis of the hypertensive disorders of pregnancy: Statement from the International Society for the Study of Hypertension in Pregnancy (ISSHP) Hypert Pregnancy 2001; 20: ix-xiv.

[2] Villar J, Say L, Gulmezoglu AM, et al. Eclampsia and preeclampsia: a health problem for 2000 years. In: Critchley $\mathrm{H}$, MacLean A, Poston L, Walker J, Eds. Pre-eclampsia. RCOG Press: London, England, 2003: pp. 57-72.

[3] Meis PJ, Goldenberg RL, Mercer BM, et al. The preterm prediction study: risk factors for indicated preterm births. Maternal-Fetal medicine units network of the national institute of child health and human development. Am J Obstet Gynecol 1998; 178: 562-7.

[4] Kotz J, Parker E, Kaufman MS. Treatment of recurrent and threatened abortion. Report of two hundred and twenty-six cases. J Clin Endocrinol 1941; 1: 838-49.

[5] Shute E. Vitamin E and premature labor. Am J Obstet Gynecol 1942; 44: 271-9.

[6] Rahimi R, Nikfar S, Rezaie A, Abdollahi M. A meta-analysis on the efficacy and safety of combined vitamin $\mathrm{C}$ and E supplementation in preeclamptic women. Hypertens Pregnancy 2009; 28: 41734 .

[7] Scholl TO, Chen X, Sims M, Stein TP. Vitamin E: maternal concentrations are associated with fetal growth. Am J Clin Nutr 2006; 84: $1442-8$.

[8] Hubel CA, Roberts JM, Taylor RN, et al. Lipid peroxidation in pregnancy: new perspectives on pre-eclampsia. Am J Obstet Gynecol 1989; 161: 1025-34.

[9] Chappell LC, Seed PT, Briley AL, et al. Effect of antioxidants on the occurrence of pre-eclampsia in women at increased risk: a randomised trial. Lancet 1999; 354: 810-6.

[10] McCance DR, Holmes VA, Maresh MJA et al. Vitamins C and E for prevention of pre-eclampsia in women with type 1 diabetes (SAPIT): a randomized placebo-controlled trial. Lancet 2010; 376: 259-66.

[11] Czeizel AE, Rockenbauer M, Siffel CS, Varga E. Description and mission evaluation of the Hungarian case-control surveillance of congenital abnormalities, 1980-1996. Teratology 2001; 63: 176-85.

[12] Czeizel AE. The first 25 years of the Hungarian congenital abnormality registry. Teratology 1997; 55: 299-305.

[13] Czeizel AE, Petik D, Vargha P. Validation studies of drug exposures in pregnant women. Pharmacoepid Drug Saf 2003; 2: 409-16.

[14] Czeizel AE, Vargha P. Periconceptional folic acid/multivitamin supplementation and twin pregnancy. Am J Obstet Gynecol 2004; 191: 790-4.

[15] Puho E, Métneki J, Czeizel AE. Maternal employment status and isolated orofacial clefts in Hungary. Cent Eur J Publ Health 2005; 13: 144-8.

[16] Naeye RL, Friedman EA. Causes of perinatal death associated with gestational hypertension and proteinuria. Am J Obstet Gynecol 1979; 133: 8-12. 
[17] Buchbinder A, Sibai BM, Caritis S, et al. Adverse perinatal outcomes are significantly higher in severe gestational hypertension than in mild preeclampsia. Am J Obstet Gynecol 2002; 186: 66-70.

[18] Gagné A, Wei SQ, Fraser WD, Julien P. Absorption, transport, and bioavailability of vitamin $\mathrm{E}$ and its role in pregnant women. $\mathrm{J}$ Obstet Gynaecol Can 2009; 31: 210-7.

[19] Baker H, Frank O, Thompson AD, et al. Vitamin profile of 174 mothers and newborns of parturition. Am J Clin Nutr 1975; 28: 5965.

[20] Rumbold A, Crowther CA. Vitamin E supplementation in pregnancy. Cochrane Database Syst Rev 2005; 18(2):CD004069.

[21] Hook EB, Healy KM, Niles AM, Skalko RG. Vitamin E: A teratogen of antiteratogen? Lancet 1974; i: 809

[22] Smedts HP, de Vries JH, Rakhshandehroo M, et al. High maternal vitamin $\mathrm{E}$ intake by diet or supplements is associated with congenital heart defects in the offspring. Br J Obstet Gynecol 2009; 116: 416-23.
[23] Szilasi M, Bártfai L, Bártfai Z, et al. No association of maternal vitamin $\mathrm{E}$ intake with higher risk of cardiovascular malformation in their offspring - a population-based case-control study. Ther Adv Drug Saf 2011; 2: 77-86..

[24] Tanetta DS, Sargent IL, Linton EA, Redman CW. Vitamins C and E inhibit apoptosis of cultured human term placenta trophoblast Placenta 2008; 29: 690-6.

[25] Roland L, Gagné A, Belanger MC, et al. Existence of compensatory defense mechanism against oxidative stress and hypertension in preeclampsia. Hypertens Pregnancy 2010; 29: 21-37.

[26] Czeizel AE, Puho HE, Langmar Z, Ács N, Bánhidy F. Possible association of folic acid supplementation during pregnancy with reduction of preterm birth: a population-based study. Eur J Obstet Gynecol Reprod Biol 2010; 148: 135-40.

[27] Czeizel AE, Petik D, Vargha P. Smoking and alcohol drinking during pregnancy. The reliability of retrospective maternal selfreported information. Cent Eur J Public Health 2004; 12: 179-83.

Received: April 16, 2011

Revised: June 03, 2011

Accepted: July 27, 2011

(C) Bártfai et al.; Licensee Bentham Open.

This is an open access article licensed under the terms of the Creative Commons Attribution Non-Commercial License (http://creativecommons.org/licenses/ by-nc/3.0/) which permits unrestricted, non-commercial use, distribution and reproduction in any medium, provided the work is properly cited. 